\title{
PSICOLOGIA E CISNORMATIVIIDADE
}

PSICOLOGÍA Y CISNORMATIVIDAD

PSTCHOLOGY AND CISNORMATIVITY

\author{
Jéssica Janine Bernhardt Fuchs ${ }^{1}$, Ana Paula Silva Hining ${ }^{1}$ \\ e Maria Juracy Filgueiras Toneli ${ }^{1}$ \\ ${ }^{1}$ Universidade Federal de Santa Catarina, Florianópolis/SC, Brasil
}

\begin{abstract}
RESUMO: O objetivo neste artigo é aproximar a discussão sobre as questões de gênero que constituem o campo de saber da psicologia e as críticas dos saberes transfeministas às práticas e discursos normativos e patologizantes sobre as vivências de pessoas trans. Utiliza-se para tal análise as noções de cisgeneridade, como forma de nomear um lugar a partir do qual as identidades trans são enunciadas, e da cisnormatividade como dispositivo que regula e determina sentidos de coerência para os processos de constituição de gênero. Esses conceitos funcionam como operadores analíticos e políticos que fazem contraponto à naturalização da cisgeneridade como pressuposto fundante das verdades do gênero e dos modos de subjetivação. Problematiza-se, portanto, como a psicologia participa dos arranjos cisnormativos relacionados aos modos de reconhecimento das pessoas trans e às possibilidades de enunciação sobre suas vivências.

PALAVRAS-CHAVE: Psicologia; Gênero; Cisgênero; Cisnormatividade; Despatologização.
\end{abstract}

RESUMEN: El objetivo de este artículo es aproximar la discusión sobre las cuestiones de género que constituyen el campo del saber de la psicología, así como las críticas de los saberes transfeministas, a las prácticas y discursos normativos y patologizantes sobre las vivencias de las personas trans. Para el análisis se utilizan las nociones de cisgeneridad como forma de nombrar un lugar a partir del cual las identidades trans son enunciadas, y de cisnormatividad como dispositivo que regula y pauta un sentido de coherencia a los procesos de constitución de género. Estos conceptos funcionan como operadores analíticos y políticos que generan un contrapunto a la naturalización de la cisgeneridad como presupuesto instituyente de las verdades del género y los modos de subjetivación. Se problematiza, por tanto, cómo la psicología participa de los acuerdos cisnormativos relacionados con los modos de reconocimiento de las personas trans, así como de las posibilidades de enunciación de sus vivencias.

PALABRAS CLAVE: Psicología; Género; Cisgénero; Cisnormatividad; Despatologización.

ABSTRACT: This article aims to articulate the discussion about the gender issues that constitute psychology's knowledge field and the critiques of the trans-feminist knowledge to normative and pathological practices and discourses about the experiences of trans people. The notion of cisgenerity is used for such analysis as a way of naming a place from which trans identities are enunciated. Moreover, the notion of cis-normativity is used as an apparatus that regulates and determines meanings of coherence to the processes of gender constitution. These concepts function as analytical and political operators that make a counterpoint to the naturalization of cisgenerity as a founding presupposition of the truths of gender and the modes of subjectivation. Therefore, it is problematized how psychology participates in the cis-normative arrangements related to the modes of recognition of trans people and to the possibilities of enunciation about their experiences.

KEYWORDS: Psychology; Gender; Cisgender; Cis-normativity; Depathologization. 


\section{Introdução}

Este artigo trata da psicologia como campo de saber que possui uma dívida histórica com as trajetórias de vida e os corpos marcados no/pelo desvio das normas. Entre estas histórias, encontramos ainda fortemente tratadas sob uma lógica patologizante e excludente as pessoas trans ${ }^{1}$, até hoje inscritas em manuais psiquiátricos e de doenças na área da saúde. Pretendemos apontar questões que as perspectivas transfeministas têm colocado à psicologia, no intuito de problematizar os discursos e práticas desse campo. No que se refere às vivências trans, perguntamos: em que situações a psicologia é convocada a atuar? O que se supõe que ela pode responder?

A partir de uma análise foucaultiana, é necessário pensar como a psicologia se assentou como forma específica de conhecimento, por meio da demarcação dos sujeitos nos parâmetros da normalidade, diferenciados e valorados em termos de desajuste e desvio da norma. $\mathrm{O}$ esforço desse pensamento problematiza as condições de emergência de certos "fenômenos" como problemas sociais e denunciam o trabalho ortopédico da psicologia em relação à subjetividade (Prado \& Trisotto, 2007), o que revela menos um "dado" natural dos sujeitos do que sua produção através de tecnologias políticas específicas. Segundo Prado e Trisotto, esse modo de conhecer possibilitou ainda uma redução das questões sociais e dos processos de subjetivação a categorias e lócus psicológicos, colocando à parte sua constituição histórica e política. Nesse sentido, cabe a nós pensar, contemporaneamente, como determinadas formulações, enunciados, objetos e conceitos articulados por este campo de saber atualizam os modos de enunciação e reconhecimento das existências deslegitimadas pelas normas desde as quais são estabelecidas as verdades do gênero.

As discussões transfeministas nos fornecem elementos para compreender, por outra perspectiva, os processos de subjetivação de gênero. No conjunto desses debates, instituiu-se a ideia de "cisgeneridade", que marcou um lugar até então vazio de nome e cheio de nomeações: um lugar de enunciação desde o qual as vivências trans são caracterizadas como patológicas, falsas, confusas, imorais, irreais e ilegítimas. Para Rodovalho (2017), a cisgeneridade surgiu da necessidade de que "as pessoas que não são nós (e a partir das quais fomos nomeadas "trans") talvez precisassem de um nome também, um nome não que lhes desse existência (afinal, quem cogitaria duvidar que, por não terem nome, inexistem?)" (p. 367). Assim, esse conceito evidencia as disputas narrativas em torno das (im)possibilidades de viver e experienciar o gênero e, principalmente, dos discursos autorizados a legitimar ou não essas vivências.

No âmbito da academia, por exemplo, multiplicam-se pesquisas sobre transexualidades e travestilidades, a partir das quais são visibilizados alguns aspectos de suas existências, descritos e interpretados em análises sociais, antropológicas e também psicológicas. Contudo, críticas às formas de produção do conhecimento surgem com a tímida, porém maior, visibilidade social e política de pessoas trans, bem como sua entrada nos espaços de saber legitimados socialmente ${ }^{2}$. Estas críticas contemplam, sobretudo, o lugar desde o qual as narrativas presentes em tais análises são construídas, e o uso de pessoas trans como objeto de estudo e negação de suas contribuições teóricas e epistemológicas, pontos estes que dizem respeito, de forma geral, à negação de pessoas trans como sujeito de conhecimento (Bagagli, 2016; Dumaresq, 2014a, 2014b, 2016; Grimm, 2016a; Kaas, 2012; Stone, 1991; Stryker, 2006; Vergueiro, 2012, 2016). 
As lutas e enfrentamentos de pessoas transexuais e travestis sempre existiram e tomaram formas diversas de acordo com as possibilidades de cada contex to histórico e político, como revelam os atuais embates em torno da despatologização de suas identidades, norteados pelo protagonismo na construção de saberes, políticas e projetos referentes a suas pautas e reivindicações. A criação e uso do conceito de cisgeneridade ${ }^{3}$ - e correlatos, como cisnorma e cissexismo - aparecem desde a década de 1990, em meio aos debates pela despatologização, e se mantém como importante operador analítico e político para evidenciar os processos normativos que promovem exclusões e interpretações patologizantes sobre as existências de pessoas trans. Portanto, a cisgeneridade constitui um eixo de naturalização dos modos de organização e regulação do gênero que, imerso nas relações de poder e saber que subjugam certas identidades e narrativas em detrimento de outras, é marcada pela compulsoriedade de sua atribuição e pela normatização das relações sociais de gênero (Bagagli, 2016; Dumaresq, 2014a, 2014b; Grimm, 2016b; Jesus, 2012; Kaas, 2012).

Talvez a definição mais difundida da palavra cis seja para designar a pessoa que se identifica com o gênero designado no nascimento, enquanto uma pessoa trans não se identificaria com essa designação. Kaas (2012) define como cis "a pessoa que foi designada "homem" ou "mulher", se sente bem com isso e é percebida e tratada socialmente (medicamente, juridicamente, politicamente) como tal” (s/p), ao passo que Grimm (2015) indica ser uma categoria relativa "a pessoas cuja referencial do "próprio" sexo coincide com aquele assignado pelos discursos médico e jurídico ao nascer. Distingue binariamente homens ou mulheres, sem abrir margem para outras identificações” (p. 15). Percebe-se, assim, a ideia de um alinhamento e um efeito de coerência naturalizados, que estabiliza as categorias - homem e mulher - pela cristalização da diferença sexual e a força de discursos específicos nos processos de conformação e legitimação dos gêneros.

Contudo, sinaliza-se também que essa identificação não implica uma correspondência absoluta com as expectativas sociais acerca do gênero designado (Kaas, 2012; Rodovalho, 2017; Sant'Anna, 2017), pois todo processo de constituição de identidade e as formas de seu reconhecimento se dão por meio da negociação de sentidos, mecanismos de aceitação e rejeição. Kaas (2012) aponta que não há como mensurar esse processo, e tampouco haveria objetivo em dicotomizar essas posições, mas defende que, nos parâmetros da cisgeneridade, uma pessoa cis é "politicamente vista como "alinhada" dentro de seu corpo e de seu gênero” (s/p), o que lhe confere privilégio em relação à legitimação de sua identidade. Para Sant'Anna (2017), torna-se necessário pensar os efeitos da cisgeneridade em uma sociedade que pouco ou mal reconhece outras experiências de gênero que desviam deste marco, a partir de sua condição sociopolítica. Assim, o processo de identificação diz mais "sobre reconhecer-se homem ou mulher e ter esse reconhecimento protegido pela cisnormatividade, graças a autoridade que a relação identidade x sexo confere dentro desse sistema de expectativas" (s/p). Trata-se, portanto, de compreender essa identificação como processo de negociação coletiva e de efeitos no campo social e político, não cabendo reduzi-la a um indivíduo ou esgotá-la em uma escolha subjetiva. Como aponta Rodovalho (2017), "o foco na auto-identificação reforça a ideia de que só se necessita explicar aquilo que cruza a linha, nunca aquilo que não cruza, que deixa de cruzar" (pp. 368-369), o que constitui precisamente a desestabilização da cisgeneridade como premissa fundante e evidência natural das identidades e expressões de gênero. 
Os trabalhos de Bagagli (2016) e Vergueiro (2012) permitem compreender a cisgeneridade na produção de saberes sobre as vivências de pessoas trans e sua relação com os processos de colonização dos corpos e das subjetividades. A noção de cisgeneridade como operador analítico expressa em Vergueiro (2012) o movimento de descolonização das identidades trans, em que os discursos marcados pela norma cisgênera não sejam os únicos nem possuam a primazia de enunciar sobre as experiências de gênero consideradas por estes inconformes. Também avalia Stone (1991) que muitas das narrativas construídas sobre pessoas trans se assemelham à lógica colonial, à medida que as objetivam de maneira exótica, no processo de negação de suas subjetividades e seus próprios saberes, e exige um corpo especialista que as decodifiquem e fale por elas.

Vergueiro (2012) propõe que a cisgeneridade seja encarada como uma das possibilidades de entender o gênero, sem ocupar uma posição hierárquica em relação à qual todas as outras identidades de gênero são interpretadas e subjugadas. Para Bagagli (2016), a cisgeneridade atua como produtora da coerência sobre o gênero e, dessa forma, ocupa uma posição transcendente - a própria verdade do gênero - a partir da qual as identidades trans são capturadas na forma de patologia. Os parâmetros de qualificação dos sujeitos pressupostos na cisnorma operam por meio de diversas disjunções que só podem, assim, expressar as transgeneridades em termos de incongruência. A partir dessa exposição, podemos tensionar os saberes da psicologia, ao investigar como a cisgeneridade se revela, mesmo sem ser nomeada, em nossas produções teóricas e práticas profissionais. Isso exige não apenas constatar a posição desde a qual nos enunciamos, como psicólogas/os em sua maioria cisgêneras/os, mas atentar aos processos normativos nos quais tomamos parte ao produzir formas de valoração e reconhecimento sobre os sujeitos, através de categorizações e narrativas que as vidas costumam extrapolar.

\section{Cisnormatividade nos discursos psi}

O discurso da psicologia tem sido usado para respaldar decisões judiciais e acesso a condições mínimas de cidadania para a população trans, tais como as retificações de nome e gênero no registro civil e as avaliações para conseguir o processo de hormonização e cirurgias de modificação corporal. Apenas em 2018 é que, no Brasil, o Supremo Tribunal Federal reconheceu o direito de pessoas trans de alterar seus nomes sem a necessidade de mediação judicial e sem a comprovação da identidade de gênero como condição psicopatológica, ou seja, por meio de laudos psiquiátricos/psicológicos. Até então, especialistas e mecanismos de validação próprios a esses saberes eram frequentemente acionados para justificar e sustentar a decisão de retificação que, conforme Vieira (1998 citado por Cidade, 2016) se amparam majoritariamente nos indícios psicológicos para a análise dos casos.

A verdade do sexo e a possibilidade para adequação do sujeito trans estaria, então, em outro "lugar" que não na "natural" organização biológica e anatômica dos corpos, mas no âmbito psíquico, cujo conflito implicaria em processos mentais geradores de sofrimentos. É aí que entra a exigência do laudo psicológico, resultante de uma avaliação que deve se valer de técnicas e instrumentos para analisar situações e/ou condições psicológicas e (fornecer elementos para) responder à questão demandada. Assim como a verdade do dito sexo biológico, a procura pela verdade de um sexo psicológico se pauta nos mesmos 
parâmetros regulatórios de gênero e sexualidade, "intimamente aliada aos estereótipos de binarismo de gênero, a partir da afirmação das ditas aparências femininas ou masculinas das pessoas julgadas. Além disso, a verdade do "sexo psicológico" só se efetiva totalmente se corresponder à expectativa da heterossexualidade compulsória” (Cidade, 2016, pp. 111-112). Assim, o lugar da psicologia surge como aquele que poderá identificar e atestar a verdade do sujeito sobre seu gênero, como se essa fosse oculta a ele mesmo, necessitando ser decifrada e falada por saberes e critérios externos a sua 'consciência'. Para Bagagli (2016), a cisgeneridade aparece, então, como racionalidade que devolve sentido às existências trans, já que estas constituiriam uma falha na produção de coerência cisnormativa.

$\mathrm{Na}$ tentativa de repensar o lugar da psicologia frente a esse tipo de demanda e com base na perspectiva de despatologização das identidades trans, iniciaram-se discussões sobre o uso compulsório do laudo como dispositivo de validação e legitimação de suas vivências, bem como os efeitos de sua atribuição para além de um simples documento técnico da prática profissional. Nessa direção, alguns Conselhos Regionais de Psicologia (CRP-03, 2015; CRP-RS, 2016) lançaram notas técnicas preconizando a utilização do parecer ao invés do laudo/relatório psicológico, em situações em que este tipo de documento pudesse ser exigido para acessar determinados direitos como a retificação de nome/gênero (antes da decisão do STF) e as cirurgias de modificação corporal. O entendimento é o de que o parecer consiste em um documento mais adequado e que às/aos profissionais compete "produzir respostas, no contexto da produção de documentos, que assegurem um estatuto de reconhecimento à vivência de gênero de travestis e transexuais, recusando o diagnóstico e a normatização e estigma que ele impõe às vivências de gênero" (CRP-RS, 2016). Essa orientação define o entendimento das vivências trans como possibilidades legítimas e autodeterminadas de existência e desloca sua apreensão das lógicas cis e heteronormativas.

Os processos de normalização, embora possam se consolidar nas formas institucionais e da lei, não coincidem com estas, e se tornam aquilo que mais implicitamente confere inteligibilidade às práticas sociais, a modos de existência específicos, a identidades corporais determinadas (Butler, 2006). Nessa perspectiva, é nos efeitos produzidos por essas normas que se torna possível analisá-las e tirá-las do seu estatuto natural e atemporal. Isso porque as formas de inteligibilidade das práticas sociais de gênero vão aparecer tanto nas práticas de naturalização de um sujeito hegemônico quanto nos processos de definição daqueles sujeitos que desestabilizam, em maior ou menor grau, esse mesmo campo de inteligibilidade (Butler, 2006). Para Preciado (2014), a naturalização do arranjo "normal" do corpo biológico, à medida que inscreve as noções de feminilidade, masculinidade e desejo em regiões precisas da carne, expulsa do campo de inteligibilidade tudo o que não coincide com esse sistema de reconhecimento. Tornam-se, pois, não apenas violações da natureza, mas violações morais. Assim, a produção do sujeito como corpo sexuado seria efeito de uma complexa tecnologia social, que engendra processos de manutenção da diferença sexual nos corpos, através de discursos, práticas e instituições que estabelecem suas fronteiras e materializam sua produção como natural.

Como então a psicologia como campo de saber toma parte nessa maquinaria de produção das verdades sobre o gênero e os sujeitos? Como seu conjunto de discursos e práticas se articula nos pressupostos da cisnorma e heteronorma? Com base nas reflexões transfeministas, entendemos que não se trata somente de pensar uma atuação voltada para pessoas trans, como uma particularidade a ser garantida no escopo genérico das ações e práticas 
psicológicas, ainda que seja necessário que estas estejam contempladas em nossos fazeres e no acesso a formas de atenção que prezem pela sua autonomia, desejos e demandas. Ir além disso significa compreender que as tecnologias sociais de gênero prefiguram modos de existência que não dizem somente daqueles cujas vidas foram enquadradas nos porões da "anormalidade", do "distúrbio psicológico", da "manifestação psicótica" até os mais atuais e sutis "fenômeno psi" e "forma epidêmica de histeria", mas dos dispositivos que regulam e produzem suas fronteiras. De acordo com Grimm (2016b), o cerne do transfeminismo "é o entendimento que não basta oferecermos formas de adequar pessoas trans nos padrões sociais impostos, mas que precisamos transformar os padrões sociais impostos para que possam acolher e dar inteligibilidade à multiplicidade de corpos trans" (s/p).

Mattos e Cidade (2016) apontam como os desdobramentos da chamada psicologia científica se assentaram na divisão binária e cisheteronormativa para compreender a constituição dos sujeitos generificados, fazendo menção às principais teorias do desenvolvimento. Conforme as autoras, o gênero, quando não está ausente como vetor de análise nessas perspectivas, aparece como algo derivado e intrínseco ao desenvolvimento humano, pressuposto na relação automática do gênero como desdobramento de sexo. Mesmo nas perspectivas que relacionam processos de aprendizagem e socialização na constituição de papéis sociais femininos e masculinos, a disjunção biológico-social ainda aloca o corpo em um âmbito pré-discursivo e desconsidera as dimensões políticas e de poder nas relações sociais. Nesse sentido, a patologização das diferenças de gênero no discurso psi nos faz perceber como este se estrutura desde uma racionalidade que oculta a si mesma à medida que viabiliza certos processos subjetivos como normais e saudáveis.

Como vamos responder às demandas de pessoas trans quando nossos parâmetros de sujeito e nossa escuta são treinadas em referências cisnormativas? Não é incomum que estas, ao procurarem acompanhamento psicológico, sejam desacreditadas em suas vivências, 'aceitas com certa estranheza' ou mesmo usadas para satisfazer as dúvidas e curiosidades de psicólogas/os cis, que compõem a maior parte desta categoria profissional. Contudo, vale ressaltar que as referências cisnormativas nos discursos da psicologia também se devem ao fato de os saberes construídos pelas próprias pessoas trans não terem a mesma legitimidade que os cânones cisgêneros e por estas não ocuparem, na mesma proporção, espaços sociais de poder e decisão, incluídas aí uma diversidade de categorias profissionais ${ }^{4}$. Para Vergueiro (2012), os processos de exclusão e ausência de pessoas trans nas esferas de produção de conhecimento e decisão mostram o aspecto político da cisgeneridade. Isso revela, para Grimm, (2016a) uma hierarquia epistêmica, a partir da qual a cisgeneridade é tomada como modelo de interpretação das relações de gênero e que confere às pessoas cisgêneras a legitimidade de enunciação sobre as verdades atribuídas a essas relações. A força do desígnio e da regulação cisnormativa se mostra por meio de discursos psi e nos convoca como profissionais a questionar: como pensar criticamente com base nos mesmos termos da cisnormatividade, que concretiza e perpetua processos de exclusão, apagamento e estigmatização de pessoas trans? 


\section{Vivências trans, parâmetros cis}

Mesmo após mudanças institucionais acerca da despatologização das identidades trans, reflexo das lutas travadas por grupos e movimentos sociais, nos deparamos com a manutenção de determinados mecanismos patologizantes que, a despeito de sofrerem alterações em sua nomenclatura, carregam ainda um ranço classificador e homogeneizador das vivências trans. Em âmbito internacional, a retirada do termo nosológico 'transtorno de identidade de gênero' do DSM-5 (APA, 2014) é substituída pela categoria de disforia, cujo critério expressa um sofrimento inerente à chamada 'condição transexual', derivado da ideia de inadequação entre um 'sexo biológico' e um 'sexo psicológico'. Segundo Jesus (2016), fundamentalmente a ideia patologizante se mantém, "pois considera que as pessoas trans vivem, naturalmente, uma insatisfação e um desprazer com o seu gênero, o que não é o caso. $O$ sofrimento da pessoa trans não é decorrente do gênero com o qual ela se reconhece, mas da reação agressiva e despersonalizadora da sociedade ante às identidades trans" (p. 550). Em um movimento semelhante, prevê-se para o CID (OMS, 1997), até 2022, a retirada definitiva da transexualidade do rol de transtornos mentais para ser compreendida no campo da saúde sexual e, assim, manter a possibilidade de acesso aos sistemas de saúde através de um diagnóstico.

No Brasil, nos deparamos com conflitos e mudanças constantes diante das demandas de despatologização e, portanto, consideramos necessário trazer esses embates para discutir e compreender as diferentes forças e narrativas em jogo. A resolução mais recente do Conselho Federal de Psicologia (CFP, 2018) define as normas de atuação para profissionais de psicologia em relação às pessoas transexuais e travestis. Este é o primeiro documento oficial do CFP que abarca o uso dos termos "cisgênero" e "cisnormatividade" para subsidiar suas práticas, a partir da noção que a cisnorma opera como um dispositivo regulador das expressões de gênero, calcado nas divisões binárias e na heterossexualidade compulsória. Além disso, legitima a autodeterminação de pessoas trans, extrapolando, assim, a ideia de despatologização reduzida a um mero ato não discriminatório.

Antes dessa posição, o CFP havia lançado uma nota técnica sobre a atuação profissional no processo transexualizador, no qual eram previstos no mínimo dois anos de acompanhamento psicológico obrigatórios no Sistema Único de Saúde (Ministério da Saúde, 2013). Nesse caso, caberia ao espaço da psicoterapia o acompanhamento da pessoa nas suas decisões relativas às modificações corporais e na elaboração de seu sofrimento, sem centrar ou reduzir o atendimento às questões cirúrgicas especificamente. Ainda que se paute em uma perspectiva integral de saúde e despatologizante na atenção às pessoas trans, inclusive na afirmação da autonomia neste processo, coloca a psicoterapia como "fundamental para a tomada de decisão na realização do processo trans" (CFP, 2013, p. 2), balizada pela exigência e reconhecimento da categoria médica de que a psicologia integre o quadro de profissionais da equipe multidisciplinar do processo. Estabelece-se, ainda, a/o psicóloga/o como alguém que deve "atuar como ferramenta de apoio ao sujeito, de modo a ajudá-lo a certificar-se da autenticidade de sua demanda, englobando todo o seu contexto social" (CFP, 2013, p. 3). Esse posicionamento foi alvo de críticas, bem expostas nos questionamentos de Kaas (2013): "O que seria essa certificação autêntica? Que critérios o psicólogo irá usar para determinar tal autenticidade?” (s/p). A autora coloca isso como um paradoxo, cuja suposta autonomia está condicionada à verificação, em que as/os profissionais psi são aquelas/es “que irão nos garantir a certeza de nossos desejos” (Kaas, 2013, s/p). 
Tomemos a nota como exemplo para evidenciar a compulsoriedade do acompanhamento, tido como requisito às pessoas integrantes no programa do processo transexualizador, com interesse em modificar seu corpo de alguma forma. Contudo, a integralidade da atenção prevista na portaria do Ministério da Saúde (2013) - atentar para a diversidade de questões trazidas pelos sujeitos, além da própria intervenção cirúrgica - necessita, ao mesmo tempo, ser objetivada por meio dos diagnósticos de 'transexualismo' (no caso de modificações cirúrgicas) e 'transexualismo' ou 'transtorno não especificado da identidade sexual' (no caso da hormonioterapia). O diagnóstico visa atestar uma condição psicopatológica, relativa à definição de 'transexualismo', que pautou o Conselho Federal de Medicina (CFM) até recentemente: "desvio psicológico permanente de identidade sexual, com rejeição do fenótipo e tendência à automutilação e/ou autoextermínio” (CFM, 2010).

A operação de certificar-se sobre a demanda das pessoas trans nesse processo acaba, por consequência, em condição de validar suas existências mesmas, legitimando-as como verdadeiras e então autorizadas a submeter-se a tais modificações. Os trabalhos de Bento (2006) e Borba (2014) mostram como os processos de validação das vivências trans se articulam por meio de discursos que figuram a imagem da 'transexualidade verdadeira', que traz à tona as disputas narrativas entre os discursos da autodeterminação de pessoas trans e os saberes especialistas. Essas disputas dizem, portanto, das contínuas negociações de sentidos sobre os parâmetros de verdade acerca das identidades trans, nas quais se cria um campo de inteligibilidade para algumas vivências, ao passo que exclui outras: "com isso temos uma função dupla desta metodologia: para haver o transexual verdadeiro há a necessidade da existência daquele que não o é, portanto, falso" (Oliveira, 2015, p. 137). No que se refere à psicologia, tais mecanismos e disputas nos dizem menos das supostas verdades que creditamos a determinadas experiências e mais dos modos de enunciar a realidade dos processos de constituição de gênero e das formas de reconhecimento dos sujeitos.

A trelada à certificação de suas demandas e desejos, reside a ideia de que as pessoas trans submetidas a essas intervenções corporais possam se arrepender e com isso desencadear intenso sofrimento psíquico, como ideações suicidas, além da confirmação do diagnóstico diferencial, em que a transexualidade não esteja presente, por exemplo, como um quadro psicótico. Kaas (2013) questiona os mecanismos de atribuição dos processos de sofrimento, afirmando que os expressivos índices de suicídio na população trans se relacionam com as condições extremamente precarizadas de existência, por esta ser tratada "como a escória social” (s/p). Nessa direção, Bagagli (2017a) afirma que a ideia de arrependimento nos leva à necessidade de discutir os conflitos e as dúvidas relativas ao processo de transição por outra ótica: a da naturalização da cisgeneridade. Para a autora, assume-se uma exigência em verificar as certezas de pessoas trans sobre seus corpos e identidades pela produção de uma vivência verdadeira da transexualidade, como se houvesse uma forma única de vivê-la, atribuível a todas as pessoas trans. Nesse movimento, as pessoas trans são destituídas de autonomia pela antecipação da possibilidade de arrependimento, justificando-se, assim, a existência de protocolos e sistemas de veridição. A autora aponta o processo de determinação de gênero para além de "uma saída do armário da cisgeneridade" (s/p) e o debate acerca do sofrimento nos processos de regulação cisnormativos: 
Porque, aliás, não se coloca a cisgeneridade nos mesmos termos em que colocamos a transgeneridade, a saber, do sujeito ser instado a estabelecer uma "escolha" subjetiva com base em um saber sobre si, uma "decisão" de si para si supostamente extremamente delicada em relação à sua própria vida? Porque não se discute os arrependimentos de anos de "armário", de imposição da cisgeneridade? Não seria exatamente porque não se enxerga o "estar no armário” em termos de tomada de decisão? Como se a decisão só pudesse estar em poder sair dele, enquanto a sua permanência é tomada como pressuposta. (Bagagli, 2017a, s/p)

A partir disso, constatamos que pode haver múltiplas formas de viver o gênero, mas apenas uma de cobrá-la. Encontra-se no discurso patologizador uma lógica semelhante à da manutenção da disforia como condição inerente ao 'ser trans', como forma de sofrimento associado a um estado psíquico interno, derivado da própria transexualidade e/ ou travestilidade. Dissocia-se, aqui, as vivências de pessoas trans das experiências adversas que estas experienciam em um contexto estruturalmente desfavorável e insensível a suas existências, assim como as condições de vida que constituem suas possibilidades de cidadania e sujeito de direitos. A ideia de sofrimento se torna então central para qualificar suas identidades em termos de desconforto, aversão e rejeição ao próprio corpo - efeito da produção de congruência e saúde assumidas na cisgeneridade. No que referimos anteriormente à figura da 'transexualidade verdadeira', Bagagli (2018) acrescenta que a ideia mesma de sofrimento se tornou uma espécie de elemento medidor dos desejos dos sujeitos em realizar alterações corporais e que, consequentemente, acaba por reforçar as (in)suficiências das pessoas trans. Dessa forma, a narrativa sustenta que só se pode ser uma pessoa trans de verdade (ou julgada mais verdadeira) quanto mais intensamente é vivenciada uma inadequação 'interna' que se materializa em sofrimento. De acordo com Tenório e Prado (2016), a correlação linear entre patologização das identidades trans e sofrimento é falsa, uma vez que os desejos pelas alterações corporais não implicam de forma inequívoca modos de sofrer associados à aversão e indiferença ao corpo, ou mesmo denotam a impossibilidade de expressar seu gênero socialmente. Da mesma maneira, segundo os autores, despatologizar não significa ignorar possíveis sofrimentos em suas trajetórias de vida.

Bagagli (2018) reconhece que a questão do sofrimento possa ter historicamente ocupado a posição de uma forma de visibilizar as demandas de pessoas trans, assim como de tornar suas existências reconhecíveis. Contudo, adverte que "é preciso fazer a crítica quando este modelo de reconhecimento pelo sofrimento começa a ser usado contra nós, a partir do momento em que o próprio modelo de reconhecimento passa a ser usado para o nosso não-reconhecimento" (s/p), em que se refere aos reducionismos pressupostos nas vivências trans em relação com seus processos de transição (como se todos os processos se dessem de igual maneira e implicando as mesmas decisões).

A partir disso, nota-se que as noções subjacentes às identidades trans nos coloca a psicologia, a psicanálise, a psiquiatria - na posição de procurar explicações, entender sua complexidade e se debater com a sua possibilidade. Essa última não vem senão com um alto custo para quem não está no posto do discurso autorizado: o que a pessoa trans pode dizer dela mesma e sob que condições? Até onde autorizamos nós, "fiscais de gênero" (Bagagli, 2016, p. 96), que esta esteja presente na narrativa da própria história e, por consequência, na história coletiva? 
Se pensarmos a obrigatoriedade do acompanhamento psicológico no processo transexualizador para que pessoas trans possam, se autorizadas, acessar minimamente um direito que diz respeito à própria existência, como encaramos esse lugar na psicologia? Se uma das bases de nosso trabalho é, em sua variedade de termos e concepções, o sujeito desejante e se encontramos na formação de vínculo nossa possibilidade de atuação, como se dá um acompanhamento que traz em sua base a compulsoriedade? Se a matriz cisgênera e heterossexual constitui o eixo regulador das práticas e discursos da psicologia frente ao gênero e a sexualidade, podemos assumir que esta dá as condições e os termos sob os quais outros modos de existência serão compreendidos e julgados. É por isso que a compulsoriedade do acompanhamento aliada à figura do psicodiagnóstico por meio do laudo não pode ser reduzida a seu aspecto instrumental ou à condição de exigência, mas a elementos saturados de sentido: o laudo como atestado material da patologização do gênero e a compulsoriedade como a força discursiva da psicologia na definição das posições autorizadas a enunciar sobre as vivências de gênero.

É importante salientar que essas discussões e seus efeitos na prática profissional podem tomar outros contornos, agora que o Conselho Federal de Medicina, a partir da nova Resolução 2.265/20195 , altera seu entendimento tanto sobre as pessoas trans quanto sobre o acompanhamento exigido nos serviços de atenção a essa população. Mais de duas décadas depois, o CFM extingue a noção de 'transexualismo' e passa a considerar a categoria trans na forma de incongruência de gênero, expressa na resolução como "a não paridade entre a identidade de gênero e o sexo ao nascimento” (CFM, 2019). Atesta ainda o reconhecimento das pessoas trans sobre o próprio gênero, porém perpetua a classificação das vivências e relações com o corpo em termos biomédicos, além de não prescindir totalmente da ideia de diagnóstico.

Propõe-se que haja articulação entre as demandas dos sujeitos e a equipe multidisciplinar por meio de um Projeto Terapêutico Singular em cada acompanhamento. A necessidade de psicoterapia, por sua vez, fica agora condicionada à baliza, indicação e mesmo execução por um profissional da psiquiatria, colocado como responsável por realizar o acompanhamento pelo período de um ano (anteriormente eram dois) junto à equipe prevista. Na composição da equipe de referência não é mencionada a participação de profissionais da psicologia, diferente daquilo indicado na portaria do Ministério da Saúde (2013). Para Matos et al. (2020), isso representaria um velado ato médico, ao conferir à psiquiatria a atribuição de indicar a necessidade de psicoterapia, bem como a definição diagnóstica dos critérios do acompanhamento, algo por si só passível de diversas críticas. Contudo, reiteramos que independentemente das atribuições de cada categoria profissional, a compulsoriedade de um acompanhamento psicológico e/ou psiquiátrico, aliada a um saber centralizador sobre as experiências de pessoas trans, pode manter e atualizar formas de patologização, ao reafirmar a soberania de discursos calcados na cisnorma.

\section{Políticas de enunciação e reconhecimento}

Destacamos, até aqui, duas questões centrais nessa discussão: (a) a pressuposição da cisgeneridade como forma de identificação e reconhecimento dos sujeitos e (b) a nomeação e o reconhecimento dos modos de subjetivação não-cisgêneros sob a forma da patologização. A patologização se faz presente na articulação de discursos e práticas que objetivam as vidas em categorias desviantes, configurando um amplo conjunto de existências que 
passam a ser faladas pelos mesmos mecanismos que buscam sua exclusão e aniquilação. Desse modo, são produzidos mecanismos explicativos na tentativa de esmiuçá-las, definir seus traços de personalidade, comportamentos, e que prescrevem a determinado gênero parâmetros de afetos, sensações, modos de agir, sentir e pensar.

Os processos de reconhecimento se materializam numa rede de discursos, instituições, práticas e sentidos que produzem modos de subjetivação e dão contorno aos modos de vida considerados legítimos e legíveis em determinado contex to social, histórico e cultural. Eles mantêm estreita ligação com a capacidade de nomear sujeitos, pois essa nomeação depende, em algum nível, de esquemas de inteligibilidade que propiciem as condições desse reconhecimento, ou seja, do que pode aparecer enquanto legível no corpo social (e que produz a si mesmo nessa inteligibilidade) (Butler, 2015). Em relação às vivências trans, tentamos apontar algumas formas de reconhecimento e apreensão que os discursos no campo da psicologia têm perpetuado, assim como os tensionamentos desses discursos a partir de outras formas de visibilização e lutas por reconhecimento de pessoas trans, que desestabilizam dessa maneira seu campo de aparição e enunciação. Esse movimento ainda é reduzido, certamente não pela falta de críticas, mas pelos modelos cisnormativos que ainda sustentam nossos saberes.

Um dos pontos centrais desse debate é o direito à autodeterminação de suas existências e modos de vida, uma ferramenta política primordial na garantia de direitos e legitimidade de suas vivências. $\mathrm{O}$ postulado que a cisnorma coloca para as vidas trans - de não validar suas identidades e processos de auto enunciação - reflete precisamente nos modos de (re)conhecimento que as subjugam. Para que esse movimento aconteça, é preciso que se retire todo lastro de subjetividade e que se negue toda enunciação de si, como aponta Stone (1991) ao afirmar que as pessoas "transexuais são infantilizadas, consideradas ilógicas demais ou irresponsáveis para atingir a verdadeira subjetividade (p. 163). Na mesma direção, Bagagli (2014) afirma que a política da cisgeneridade é baseada na condescendência, pois as pessoas trans não são reconhecidas "enquanto um sujeito de igual consciência" (s/p). Fazendo referência ao laudo como dispositivo de significação cisgênera da incongruência das identidades trans, ela aponta a suposição intrínseca da impossibilidade de consentimento de pessoas trans sobre suas escolhas e desejos. Para a autora, é dessa maneira que as/os profissionais "garantem a própria unicidade de suas identidades cisgêneras: não é fato banal de que empiricamente serem estas as pessoas que ocupam estes espaços institucionais" (Bagagli, 20 14, s/p).

A discussão esboçada aqui passa, portanto, por compreender como o gênero é investido em uma humanidade decifrável (Butler, 2006). Como aponta a autora, a violência surge como uma demanda de desfazer o reconhecimento, pôr em xeque sua possibilidade, eliminar a contingência, de manter uma ordem de gênero - e não importa que faceta esta assuma. Moira (2017) coloca que a possibilidade de estar submetida à violência se torna constitutiva da existência e, portanto, reflete nos processos de constituição de gênero. Ela relata que "no caso de pessoas trans, isso se torna um processo eficientíssimo de enlouquecimento, a criação para o medo junto a uma vida inteira ouvindo que a compreensão que você faz de si é equivocada, impossível, já que você tem o genital que tem” (p. 18), o que também produz a investida do sofrimento por vezes no próprio corpo, que passa a ser entendido e vivido no âmbito da rejeição.

Bagagli (2017b) procura desarticular a noção de identidade e a premissa da autoidentificação dos parâmetros individualizantes. Para ela, os discursos transfóbicos que veem a autodeterminação com desconfiança se baseiam na sua associação à subjetividade, 
vista como potencialmente enganadora e falsa, ameaçadora da objetividade, ligada então à natureza, como resquício de alguma garantia 'concreta'. De acordo com a autora, "a auto identificação - produto de um processo em que o sujeito entra em relação com os sentidos (sociais e históricos) que o constitui - só se realiza a partir de marcos sociais e históricos determinados. Não uma verdade qualquer, se trata de uma verdade específica àquele que enuncia, em suas especificidades (e heterogeneidades)" (Bagagli, 2017b, s/p). A partir disso, podemos entender que a materialidade disso que chamamos subjetivo é o que confere possibilidade individual e coletiva aos sujeitos. Portanto, em relação às identidades cis e trans, a objetividade é mais reveladora da regulação normativa dos corpos do que de sua existência. Na mesma direção, Grimm (2016b) argumenta que ambas as formas de existências trans e cisgêneras se constituem por meio de tecnologias e narrativas próprias, materializadas nas possibilidades da história e da cultura, mas que "os lugares políticos dessas ficções e tecnologias são diferentes” (s/p). Agora, se deslocarmos a lógica, deveríamos nos perguntar, como pessoas e profissionais cis: nossa autoidentificação em relação à cisgeneridade não está também aí, de certa forma (em maior ou menor grau), porém automatizada? Será que a desconfiança à ideia de autodeterminação não é justamente um efeito da racionalidade cisnormativa que naturaliza e condiciona certos corpos a determinadas possibilidades de se enunciar?

\section{Considerações finais}

Arriscamos dizer que a queda de certos termos diagnósticos nos permite uma falsa sensação de estarmos "despatologizando" e que não mais encaixamos as vivências trans em critérios diagnósticos de inteligibilidade. Nossa suposição é a de que a psicologia, em suas diversas frentes, precisa se haver com os processos de subjetivação de gênero não apenas como experiências possíveis na diversidade humana, nem necessariamente como particularidade de um sujeito ou uma identidade específica, mas compreender como entendemos e definimos sujeitos generificados, a díade feminilidade-masculinidade, os ideais de homem e mulher, as supostas coerências dessa constituição e, principalmente, como esse arranjo ideológico produz e perpetua desigualdades existenciais, sociais, políticas e econômicas. Segundo Stryker (2006), no campo interdisciplinar de estudos trans, cabe analisar como essas diferenças se tornam hierarquias sociais, pois estas "nunca são meras abstrações; elas são sistemas de poder que operam em corpos reais, capazes de produzir dor e prazer, saúde e doença, culpabilização e recompensa, vida e morte” (p. 3).

Assim, tentamos trazer a cisgeneridade como um conceito necessário à psicologia e pensar as contribuições éticas e epistemológicas que a compreensão de seus mecanismos traz às nossas práticas e discursos, pois é a partir destes que se configuram os modos de enunciar e reconhecer os sujeitos. Entender os dispositivos de produção da coerência entre sexo, gênero, corpo e desejo nos coloca frente à maneira como estabelecemos um padrão de normalidade considerada saudável e correta para as experiências de gênero. A despatologização das identidades trans exige uma ruptura que envolva não somente abrir mão de um diagnóstico formal, mas compreender como tornamos um 'modo de sofrer específico', associado de forma inerente às suas vivências, sua chave de inteligibilidade primária. E, sobretudo, entender que a determinação de suas verdades não compete a nós enunciar, mas tão somente reconhecer. 


\section{Notas}

1 Termo para designar pessoas transexuais, travestis e transgêneras, utilizado aqui para abarcar a diversidade de pessoas cujas identidades não são contempladas pela cisgeneridade, sem pressupor sua homogeneização como categoria única, conforme Vergueiro (2012).

2 Trazemos a academia como instituição que acaba por balizar os saberes considerados válidos, e porque as tensões acerca da noção de cisgeneridade nesse âmbito indicam as desconfianças de saberes produzidos a partir de outros lugares, como os ativismos e movimentos sociais. Também a ausência, presença reduzida e/ou dificuldade de permanência de pessoas trans nesses espaços se relacionam com as próprias condições de deslegitimação de suas identidades, que acentuam os processos de vulnerabilização sociais e econômicos em suas trajetórias.

3 Para análise das mudanças sociais e políticas da noção de cisgeneridade, ver Dumaresq (2014b).

4. Na psicologia e na psicanálise, temos, contudo, referências importantes como Jaqueline Gomes de Jesus, Raíssa Grimm, Céu Cavalcanti, Letícia Lanz e João Nery. João, falecido em 2018, escritor e militante dos direitos da população trans, era formado em psicologia. Teve seu registro profissional cassado por se assumir homem trans há quase 50 anos.

5 Para análises e críticas mais específicas da nova resolução do CFM, ver Bagagli (2020) e Matos et al. (2020).

\section{Referências}

American Psychological Association - APA. (2014). Manual diagnóstico e estatístico de transtornos mentais - DSMV.(5a ed.). Porto Alegre: Artmed.

Bagagli, B. P. (2014). O que é um laudo? Um pouco sobre a recusa à cidadania cirúrgica. Transfeminismo. Recuperado de https://bit.ly/2EQ4LIO.

Bagagli, B. P. (2016). A diferença trans no gênero para além da patologização. Periódicus, 1(5), 87-100.

Bagagli, B. P. (2017a). Sobre “destransição”, arrependimento e cisgeneridade. Transfeminismo. Recuperado de https://bit.ly/2NQijq4.

Bagagli, B. P. (2017b). Uma reflexão sobre auto identificação de gênero e verdade. Transfeminismo. Recuperado de https://bit.ly/2IZuMZE.

Bagagli, B. P. (2018). Sofrimento como critério de exclusão: as formas de reconhecimento subjetivo pela "disforia" que precisam ser superadas. Medium. Recuperado de https://bit.ly/2tV4P34. Bagagli, B. P. (2020). Sobre a Resolução nº 2.265 do Conselho Federal de Medicina. Transfeminismo. Recuperado de https://bit.ly/2KARCFO

Bento, B. (2006). A reinvenção do corpo: sexualidade e gênero na experiência transexual. Rio de Janeiro: Garamond. 
Borba, R. (2014). (Des)aprendendo a "ser": trajetórias de socialização e performances narrativas no processo transexualizador, Tese de Doutorado, Programa Interdisciplinar de Pós-graduação em Linguística Aplicada, Universidade Federal do Rio de Janeiro, Rio de Janeiro, RJ.

Butler, J. (2006). Deshacer el género. Barcelona, ESP: Paidós.

Butler, J. (2015). Quadros de guerra: quando a vida é passível de luto. Rio de Janeiro: Civilização Brasileira.

Cidade, M. L. R. (2016). Nomes (im)próprios: registro civil, norma cisgênera e racionalidades do Sistema Judiciário. Dissertação de Mestrado, Programa de Pós-graduação em Psicologia, Universidade Federal do Rio de Janeiro, Rio de Janeiro, RJ.

Conselho Federal de Medicina - CFM. (2010). Resolução CFM n $n^{\circ}$ 1.955/2010. Dispõe sobre a cirurgia de transgenitalismo e revoga a Resolução CFM no 1.652/02. Recuperado de https:// bit.ly/2kvU3sU.

Conselho Federal de Medicina - CFM. (2019). Resolução CFM nº 2.265/2019. Dispõe sobre o cuidado específico à pessoa com incongruência de gênero ou transgênero e revoga a Resolução CFM n ${ }^{\circ}$ 1.955/2010. Recuperado de https://bit.ly/2zxUBf6

Conselho Federal de Psicologia - CFP. (2013). Nota técnica sobre processo transexualizador e demais formas de assistência às pessoas trans. Brasília. Recuperado de https://bit.ly/2JfjsaM.

Conselho Federal de Psicologia - CFP. (2018). Resolução $n^{\circ} 1$ de 29 de janeiro de 2018. Brasília. Recuperado de https://bit.ly/2ESc3vo.

Conselho Regional de Psicologia do Rio Grande do Sul - CRP-RS. (2016). Nota Técnica do CRPRS acerca da produção de documentos psicológicos em situações de alteração/adequação de nome no registro civil e de procedimentos de modificação corporal de pessoas transexuais e travestis. Porto Alegre. Recuperado de https://bit.ly/2TzKTkG.

Conselho Regional de Psicologia da Bahia - CRP-03. (2015). Posicionamento do CRP-03 acerca da produção de relatórios em casos de alteração/adequação de nome no registro civil das travestis e das/os transexuais. Salvador. Recuperado de https://bit.ly/2IXbiF 7.

Dumaresq, L. (2016). Ensaio (travesti) sobre a escuta (cisgênera). Periódicus, 1(5), 121-131.

Dumaresq, L. (2014a). Ensaio de epistemologia transgênera. Transliteração. Recuperado de https://bit.ly/2ESin5B.

Dumaresq, L. (2014b). O cisgênero existe. Transliteração. Recuperado de https://bit.ly/2ETpafA.

Grimm, R. E. (2015). Abrindo os códigos do tesão: feitiços de resistência entre o transfeminismo pós-pornográfico. Tese de Doutorado, Programa de Pós-graduação em Psicologia, Universidade Federal de Santa Catarina, Florianópolis, SC.

Grimm, R. E. (2016a). A Violência Cisgênera E Suas Hierarquias. Transfeminismo. Recuperado de https://bit.ly/2HnLHCV.

Grimm, R. E. (2016b). O conceito de cisgeneridade e o transfeminismo. Blogueiras feministas. Recuperado de https://bit.ly/2tWuhVG.

Jesus, J. G. (2012). Orientações sobre identidade de gênero: conceitos e termos. Guia técnico sobre pessoas transexuais, travestis e demais transgêneros, para formadores de opinião. Brasília. Recuperado de https://bityli.com/Fu6oW

Jesus, J. G. (2016). Operadores do direito no atendimento às pessoas trans. Rev. Direito E̊ Práxis, 7(15), 537-556. 
Kaas, H. (2012). O que é cissexismo? Transfeminismo. Recuperado de https://bit.ly/2EHXBUV. Kaas, H. (2013). Sobre a nota do CFP: Patologização das identidades trans* e compulsoriedade da psicoterapia no processo transexualizador. Gênero à deriva. Recuperado de https://bit.ly/2TCCHQA.

Matos, A., Bento B., Teixeira, F. B., Tagliamento, G., Perucchi, J., Prado, M. A. M., Toneli M. J. F. et al. (2020). Análise da Resolução 2265 de 20 de setembro de 2019 - Resolução produzida pelo Conselho Federal de Medicina. Núcleo de Direitos Humanos e Cidadania LGBT. Belo Horizonte: Universidade Federal de Minas Gerais. Recuperado de https://bit.ly/2xcK9sv

Mattos, A. R. \& Cidade, M. R. (2016). Para pensar a cisheteronormatividade na psicologia: lições tomadas do transfeminismo. Periódicus, 1(5), 132-153.

Moira, A. (2017). Destino amargo. In A. Moira, M. Rocha, T. Brant, \& J. Nery (Orgs.), Vidas trans: a coragem de existir (pp. 17-55). Bauru, SP: Astral Cultural.

Sant'Anna, Y. (2017). Cisgeneridade e identidade. Transfeminismo. Recuperado de https:// bit.ly/2Hhkvpb.

Oliveira, A. L. G. (2015). Luta pela despatologização. In B. Bento \& A. V. Félix-Silva (Orgs.), Desfazendo gênero: subjetividade, cidadania, transfeminismo (pp. 133-143). Natal: EDUFRN.

Organização Mundial da Saú de - OMS. (1997). CID-10: Classificação Estatística Internacional de Doenças e Problemas Relacionados à Saúde(Vol. 2). 10a rev. São Paulo: Universidade de São Paulo.

Ministério da Saúde. (2013). Portaria $n^{\circ}$ 2.803, de 29 de novembro de 2013. Redefine e amplia o Processo Transexualizador no Sistema Único de Saúde (SUS). Brasília, DF: Autor. Disponível em: https://bit.ly/1Bipb2P.

Prado, K. \& Trisotto, S. (2007). A Psicologia como disciplina da norma nos escritos de M. Foucault. Revista Aulas: Dossiê Foucault, 1(3), 1-14.

Preciado, P. B. (2014). Manifesto Contrassexual. São Paulo: N-1 edições.

Rodovalho, A. M. (2017). O cis pelo trans. Revista Estudos Feministas, 25(1), 365-363.

Stone, S. (1991). The empire strikes back: A posttranssexual manifesto. Duke University Press. Recuperado de https://bityli.com/BChdj

Stryker, S. (2006). (De)subjugated Knowledges: An introduction to transgender studies. In S. Stryker \& S. Whittle (Orgs.), The Transgender Studies Reader (pp. 1-19). New York: Routledge.

Tenório, L. F. P. \& Prado, M. A. M. (2016). As contradições da patologização das identidades trans e argumentos para a mudança de paradigma. Periódicus, 1(5), 41-55.

Vergueiro, V. (2012). Pela descolonização das identidades trans*. In Anais do VI Congresso Internacional de Estudos Sobre a Diversidade Sexual e de Gênero da ABEH. Salvador, ABEH. Recuperado de https://bityli.com/BuLqR

Vergueiro, V. (2016). Por inflexões decoloniais de corpos e identidades de gênero inconformes: uma análise autoetnográfica da cisgeneridade como normatividade. Dissertação de Mestrado, Programa Multidisciplinar de Pós-graduação em Cultura e Sociedade, Universidade Federal da Bahia, Salvador, BA. 


\section{JÉSSICA JANINE BERNHARDT FUCHS}

https://orcid.org/O000-0002-8383-8604

Mestre em Psicologia Social pela Universidade Federal de Santa Catarina, Psicóloga na Associação em Defesa dos Direitos Humanos com Enfoque na Sexualidade (ADEH - Florianópolis/SC)

Endereço: PPGP-UFSC - Campus Universitário - 88040-500 Florianópolis - SC.

E-mail: jessicab.fuchs@gmail.com

\section{ANA PAULA SILVA HINING}

http://orcid.org/0000-0003-2125-9401

Mestre em Psicologia Social pela Universidade Federal de Santa Catarina.

E-mail: anahining@gmail.com

\section{MARIA JURACY FILGUEIRAS TONELI \\ http://orcid.org/0000-0002-9311-5020}

Doutora em Psicologia Escolar e do Desenvolvimento Humano (USP)

e Pós-doutora em Psicologia Social (UFMG e UMinho/PT), Professora Titular do PPGP-UFSC.

E-mail: juracy.toneli@gmail.com

\begin{tabular}{|c|c|}
\hline Histórico & $\begin{array}{l}\text { Sulbmissão: 07/03/2019 } \\
\text { Aceite: 20/04/2020 }\end{array}$ \\
\hline $\begin{array}{l}\text { Contribuição } \\
\text { dos autores }\end{array}$ & $\begin{array}{l}\text { Concepção: J.J.B.F. } \\
\text { Coleta de dadlos: J.J.B.F. } \\
\text { Análise de dados: J.J.B.F. } \\
\text { Elaboração do manuscrito: J.J.B.F., A.P.S.H. } \\
\text { Revisões de conteúdlo intelectual importante: A.P.S.H., } \\
\text { J.J.B.F., M.J.F.T. } \\
\text { Aprovação final dlo manuscrito: M.J.F.T. }\end{array}$ \\
\hline $\begin{array}{l}\text { Consentimento } \\
\text { de uso de imagem }\end{array}$ & Não se aplica. \\
\hline $\begin{array}{l}\text { Aprovação, ética } \\
\text { e consentimento }\end{array}$ & Não se aplica. \\
\hline Financiamento & $\begin{array}{l}\text { Jéssica Janine Bernhardt Fuchs - Fapesc (edital No } \mathrm{N}^{\mathrm{O}} \mathrm{05/2015}- \\
\text { PROGRAMA FAPESC DE RECURSOS HUMANOS EM CTI) } \\
\text { e CAPES (programa CAPES-DS). } \\
\text { Maria Juracy Filgueiras Toneli - Bolsa PQ1A. } \\
\text { Ana Paula Silva Hining - CAPES DS, edital de } 2018 .\end{array}$ \\
\hline
\end{tabular}

